\title{
Uso de inoculantes como estrategia de manejo agronómico sustentable en fincas de papa (Solanum tuberosum) de la región Lima
}

\author{
Use of inoculants as a strategy for sustainable agronomic \\ management in potato (Solanum tuberosum) farms at Lima region
}

\author{
Sergio Eduardo Contreras-Liza ${ }^{*}$, Huberto Noriega Córdoba ${ }^{1}$, Alberto Valenzuela Muñoz ${ }^{1}$, \\ Luis Arias Martínez" ${ }^{1}$ Doris Zúñiga Dávila², Sady García-Bendezú2
}

\begin{abstract}
RESUMEN
La papa es un cultivo originario del Perú con amplia diversidad genética y que actualmente se desarrolla en pequeñas parcelas en más de 300 mil hectáreas a nivel nacional generando empleo rural. Por ello es prioritario evaluar la sustentabilidad de los sistemas de producción en concordancia con prácticas agronómicas que sean amigables al medio ambiente. Se realizó una investigación para determinar el efecto que podría tener la inoculación de cepas bacterianas nativas sobre el comportamiento agronómico de la papa en fincas productoras de la región Lima. Se instalaron ensayos agronómicos en condiciones de campo bajo el Diseño de Bloques Completos y se evaluaron características agronómicas y productivas del cultivo. Previamente, se determinó el grado de sustentabilidad ambiental de las fincas productoras de papa en Lima, mediante el análisis multicriterio de Sarandón. Se concluyó que las fincas tienen un bajo nivel de sustentabilidad ambiental, con un valor de 1,52 en la escala ponderada de indicadores utilizada, y que es necesario implementar estrategias que reduzcan la vulnerabilidad del cultivo de papa en cuanto a la conservación de la vida del suelo y manejo de la agrodiversidad. Mediante inoculación con la cepa Azotobacter sp. se obtuvieron diferencias significativas $(P<0,05)$ con respecto al control sin inoculación, aumentando el rendimiento de tubérculos y el peso comercial por hectárea, con un menor daño por mosca minadora (Liriomyza huidobrensis) frente al control. Se concluye que la utilización de bacterias promotoras del crecimiento en la papa puede ayudar a reducir la vulnerabilidad del cultivo, incrementando el nivel de sustentabilidad ambiental a nivel de finca.

Palabras clave: Sustentabilidad ambiental, análisis multicriterio, bacterias promotoras del crecimiento, agroecología.
\end{abstract}

\begin{abstract}
The potato is a crop originating in Peru with a wide genetic diversity and that currently grows in small farms in more than 300 thousand hectares in Peru, generating rural employment, being therefore a priority to evaluate the sustainability of production systems in accordance with agronomic practices that are environmentally friendly. A research was carried out to determine the effect of inoculation of native bacterial strains on the agronomic performance of potato farms in the Lima region, with agronomic trials being installed in field conditions under the complete blocks design and evaluating agronomic characteristics and productive aspects of the crop. Previously, the degree of environmental sustainability of the potato farms in Lima region was determined through the Sarandon multicriteria analysis. It was determined that the potato farms at Lima region have a low level of environmental sustainability with a value of 1.52 in the weighted scale of indicators used and that it is necessary to implement strategies that reduce the vulnerability of potato farms in terms of conservation of soil life and management of agro-biodiversity. By inoculation with strain AZO16M2 (Azotobacter sp.) significant differences $(P<0.05)$ were obtained with respect to control without inoculation, increasing the tuber yield and the commercial weight per hectare, with less damage by leafminer fly (Liriomyza huidobrensis) compared to control. It is concluded that the use of growth promoting bacteria in the potato farms can help to reduce the vulnerability of the crop, increasing the level of environmental sustainability at the farm level.

Key words: Environmental sustainability, multicriteria analysis, plant growth promoting rhizobacteria, agroecology.
\end{abstract}

\section{Introducción}

El Perú es centro de origen de la papa y sus parientes silvestres, por lo que es conveniente desa- rrollar nuevas tecnologías de manejo agronómico con menor impacto sobre el ecosistema. Por otro lado, el uso de plaguicidas químicos en la papa está aumentando en los países en desarrollo, a la vez que

\footnotetext{
1 Universidad Nacional José Faustino Sánchez Carrión. Av. Mercedes Indacochea 609. Huacho, Perú.

2 Universidad Nacional Agraria La Molina. Av. La Universidad. La Molina Lima-Perú.

* Autor para correspondencia: scontreras@unjfsc.edu.pe
}

Fecha de Recepción: 15 marzo, 2019.

Fecha de Aceptación: 31 agosto, 2019. 
los agricultores intensifican la producción (FAO 2008). Las prácticas agrícolas sostenibles son la respuesta a los problemas multifacéticos que se han originado por el uso prolongado e indiscriminado de productos químicos para mejorar la producción de los cultivos durante muchas décadas. Por esta razón se ha acentuado la búsqueda de opciones eco amigables para reemplazar los fertilizantes químicos y pesticidas (Prashar et al., 2014).

De acuerdo a Sessitsch y Mitter (2015), en muchas partes del mundo donde la agricultura de bajos ingresos es una situación común y el mejoramiento del germoplasma o las prácticas agrícolas están poco disponibles, un mejor uso de las funciones de los microbiomas de las plantas apoyará especialmente la producción agrícola y fomentará la bioeconomía en los países menos desarrollados que utilicen inoculantes microbianos y que puedan establecer colecciones de cepas para los ambientes locales.

En un estudio de los sistemas de cultivo biodinámico, orgánico y convencional realizado durante más de 20 años, Mäder et al. (2002) hallaron que los rendimientos de los cultivos de papa y cereales fueron $20 \%$ menores, aunque el aporte de fertilizantes y energía se redujo en un 34 a $53 \%$ y el de plaguicidas en un $97 \%$, con una mayor fertilidad del suelo y gestión de la biodiversidad Concluyeron que las parcelas agroecológicas pueden hacer que estos sistemas sean menos dependientes de insumos externos.

Se sabe que los microorganismos del suelo agrícola ejercen una profunda influencia en el estado de fertilidad del suelo, en particular en lo que respecta a la disponibilidad de nutrientes, así como en la supresión de las enfermedades de las plantas (Kennedy y Smith, 1995). Hay evidencia de que la biodiversidad del suelo confiere estabilidad al estrés y a la perturbación (Brussaard et al., 2007), pero el mecanismo todavía no se entiende completamente. Los resultados de Turnbull, Campbell y Lazarovits (2014) mostraron que la rizósfera de la papa es una comunidad resistente y que la primera comunidad bacteriana que se establece en la raíz permanece asociada a ella, incluso cuando las plantas se colocan en el suelo con una microbiota muy diferente.

Oswald et al. (2010) demostraron en ensayos bajo condiciones controladas con Bacillus sp., los mecanismos causantes del mejor crecimiento de plantas de papa, como tuberización temprana, rápido desarrollo del área foliar y probablemente, mayor tasa de fotosíntesis. Calvo et al. (2010) realizaron una prospección de rizobacterias extraídas de la rizósfera de papas nativas que crecen en su hábitat natural en los Andes y los resultados sugirieron que son una fuente rica de antagonistas para hongos fitopatógenos, principalmente en el género Bacillus sp., con un potencial para ser utilizados en el futuro como inoculantes para mejorar el comportamiento agronómico de la papa.

De acuerdo a Arcos y Zúñiga (2015), las cepas de Bacillus subtilis y B. amyloliquefaciens nativas de la región altiplánica del Perú y Bolivia, inoculadas a plántulas de dos variedades de papa (Compis y Andina), tienen la capacidad de inhibir la infección por $R$. solani, posiblemente a través de algún mecanismo de acción antagónica o por resistencia inducida. Oswald et al. (2010) plantean que el uso de los microorganismos del suelo podría reducir la aplicación de fertilizantes en el cultivo de la papa y controlar parcialmente las enfermedades transmitidas por el suelo que afectan la producción y calidad de los tubérculos. El estudio de Hanif et al. (2015) indica que la cepa KPS-11 de B. subtilis puede ser un candidato potencial para el desarrollo de inóculos en papa, en suelos deficientes en fósforo.

Por otro lado, en la región Lima se cultivaron alrededor de 6. 211 hectáreas de papa durante la campaña agrícola 2014 con un rendimiento medio de 23,7 tha ${ }^{-1}$, según datos de la Oficina de Estudios Económicos y Estadísticos del Ministerio de Agricultura y Riego (MINAGRI, 2015). En este sistema de producción de papa se utiliza tecnología agrícola intensiva como insumos agrícolas (particularmente fertilizantes y agroquímicos), mecanización, riego, control fitosanitario y asistencia técnica, además de otros factores socioeconómicos que es necesario ponderar, para evaluar si son usados en forma racional y de acuerdo a los estándares de sustentabilidad ambiental, económica y social. Sarandón \& Flores (2014) proponen pautas metodológicas para la evaluación de la sustentabilidad de los agroecosistemas y para determinar si el proceso de la transición de sistemas convencionales hacia sistemas diversificados y sustentables está sentado en principios y procesos agroecológicos. De esta manera, los autores describen una metodología para la construcción y uso de indicadores de sustentabilidad. Las metodologías denominadas 
de "investigación de sistemas prediales o de finca" enfatizan la comprensión de los sistemas agrícolas tradicionales como punto de partida, evalúan los antecedentes de la zona, realizan exámenes en el terreno que incluyen entrevistas a los agricultores respecto a las características del predio y analizan los motivos por los cuales emplean métodos particulares de producción (Altieri, 1997).

Por lo tanto, el propósito de la investigación fue responder a las siguientes interrogantes: ¿Qué factores afectan la sustentabilidad ambiental en las fincas de producción de papa? ¿El uso de inoculantes se presenta como una alternativa de manejo agronómico sustentable en el cultivo de papa?

El objetivo principal de la investigación fue evaluar la sustentabilidad ambiental de las fincas productoras de papa y proponer alternativas para optimizar el sistema de producción en las condiciones de la costa central del Perú, mediante un estudio holístico desde el enfoque de sistemas que permita integrar el análisis del medio natural, los procesos productivos y el comportamiento histórico del productor de papa. Se evalúa particularmente el impacto que pueda tener el uso de inoculantes como estrategia de manejo agronómico.

\section{Materiales y Métodos}

\section{Determinación del grado de sustentabilidad ambiental en las fincas de papa}

El área seleccionada para este estudio abarcó tres localidades productoras de papa en la región Lima: Barranca, Huaral y Cañete. El agroecosistema de Costa se caracteriza por presentar suelos aluviales franco arenosos con baja cantidad de materia orgánica y aptos para el cultivo de papa en temporada de invierno. La metodología para determinar los indicadores de sustentabilidad se basó en la propuesta de Sarandón (2002). Consistió en una serie de pasos que conducen como producto final, a la obtención de un conjunto de indicadores adecuados para evaluar los puntos críticos en la sustentabilidad del agroecosistema. Se consideró en este caso que los sistemas de producción agrícola sustentables proveen rendimientos sostenidos durante largo tiempo mediante el uso de tecnologías ecológicamente probadas. Los indicadores evaluados fueron los siguientes:
A. Conservación de la vida del suelo, con dos subindicadores: (A1) Rotación de cultivos y (A2) Diversificación de cultivos.

B. Riesgo de erosión. Se consideraron tres subindicadores: (B1) Cobertura vegetal, (B2) Tipo de suelo, (B3) Materia orgánica aplicada al suelo.

C. Manejo de la agrobiodiversidad. Se consideraron cuatro subindicadores: (C1) Biodiversidad temporal, (C2) Biodiversidad espacial, (C3) Biodiversidad en variedades de papa, (C4) Incidencia de plagas y enfermedades.

Se utilizó una encuesta a los productores de papa como instrumento para obtener información válida de las variables e indicadores de sustentabilidad. La encuesta consistió en un cuestionario de 70 preguntas referidas a cada una de las dimensiones de sustentabilidad a evaluar. Se entrevistó a 127 productores de papa de la región Lima: provincia de Barranca (67 agricultores), Huaral (44 agricultores) y Cañete (16 agricultores).

Las ponderaciones utilizadas para valorar y cuantificar los indicadores de sustentabilidad fueron conciliadas luego de un proceso de consulta a especialistas de los sectores agroalimentario y académico. Los valores utilizados fueron los siguientes:

$$
\begin{aligned}
\mathbf{I A}= & {[0.15(\mathrm{~A} 1)+0.15(\mathrm{~A} 2)]+[0,05(\mathrm{~B} 1)+0.10(\mathrm{~B} 2)+} \\
& 0.15(\mathrm{~B} 3)]+[0.10(\mathrm{C} 1)+0.10(\mathrm{C} 2)+0.10(\mathrm{C} 3) \\
& +0.10(\mathrm{C} 4)]
\end{aligned}
$$

La propuesta desarrollada fue la utilización de escalas de 0 a 4, siendo 0 la categoría menos sustentable y 4 la más sustentable. Independientemente de las unidades en que se obtuvieron originalmente, los valores de cada indicador se expresaron en algún valor de esta escala. En la escala cuantitativa se consideró el valor umbral de 2 como un nivel aceptable de sustentabilidad, según Sarandón y Flores (2014).

\section{Impacto del uso de inoculantes como estrategia de manejo agronómico en la papa}

Se propuso un sistema alternativo o de optimización en el cultivo de papa basado en criterios agroecológicos. En este aspecto, se analizó el uso de algunas tecnologías eco amigables, principalmente la inoculación con microorganismos, 
para optimizar el uso de fertilizantes así como para inducir resistencia sistémica y mejorar el comportamiento agronómico del cultivo de papa.

Para cumplir este propósito, se analizaron los resultados experimentales de diversos ensayos con inoculantes bacterianos, desarrollados en condiciones de campo bajo el Diseño de Bloques Completos durante las campañas de papa 2013-2014. Se realizaron pruebas estadísticas para comparar los diversos tratamientos inoculantes, a un nivel de significación estadística del 5\%. Asimismo, se utilizó información de diversas publicaciones científicas sobre uso de microorganismos promotores del crecimiento en el cultivo de papa principalmente entre los años 2000-2016, para analizar comparativamente los resultados experimentales de los ensayos realizados con inoculantes.

\section{Resultados y Discusión}

\section{Determinación del grado de sustentabilidad ambiental en las fincas de papa}

Según lo mostrado en la Tabla 1, los subindicadores de sustentabilidad ambiental considerados en el modelo tuvieron valores menores a 2, con excepción del referido a vulnerabilidad por estreses bióticos, principalmente incidencia de plagas y enfermedades (C4), cuyo valor superó ligeramente el umbral establecido. Sin embargo, el índice ponderado de sustentabilidad ambiental (IA) fue de 1,52, lo que implicaría una pobre sustentabilidad de las fincas productoras de papa en la región Lima.

Los aspectos relacionados con la gestión ambiental en los predios productores de papa se presentaron como un factor crítico que afecta notoriamente la sustentabilidad del sistema de producción en la Costa, si se tiene en cuenta que como consecuencia del cambio climático, es muy probable que las condiciones medioambientales sean poco favorables en los próximos años para el cultivo en la costa central, en caso de que las temperaturas ambientales y del suelo se incrementen.

En la Figura 1 se muestra que es necesario mejorar los índices de sustentabilidad ambiental en las fincas respecto a conservación de la vida en el suelo, riesgo de erosión y manejo de la agrobiodiversidad. Kroschel et al. (2012) proponen

\section{Indicadores de sustentabilidad ambiental}

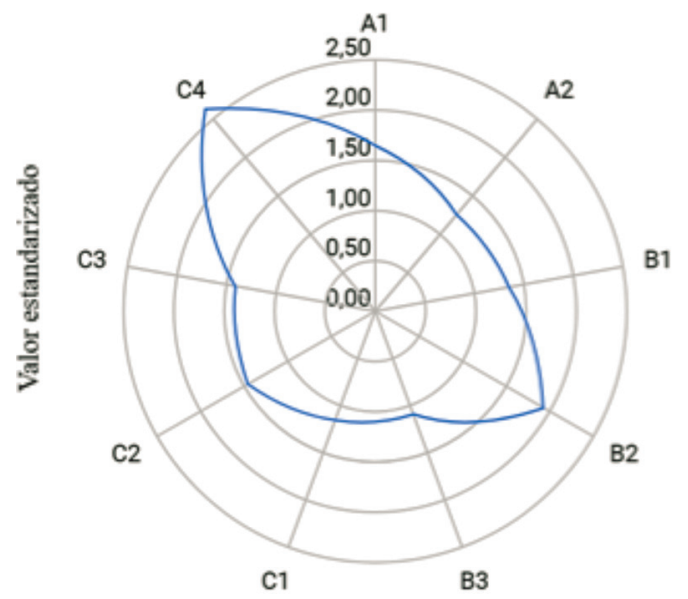

Figura 1. Indicadores de sustentabilidad ambiental para las fincas productoras de papa en la Región Lima. Valores estandarizados menores a 2 indican una sustentabilidad debajo del umbral A1, Rotación de cultivos. A2, Diversificación de cultivos. B1, Cobertura vegetal. B2, Tipo de suelo. B3, Materia orgánica aplicada al suelo. C1, Biodiversidad temporal. C2, Biodiversidad espacial. C3, Biodiversidad en variedades de papa. C4, Incidencia de plagas y enfermedades.

Tabla 1. Indicadores de sustentabilidad ambiental ${ }^{1}$ de las fincas productoras de papa en la región Lima.

\begin{tabular}{lrrrrrrrr}
\hline \multicolumn{1}{c}{ Subindicadores } & $\mathrm{n}$ & Media & Max & Min & Mediana & Rango & Pond. & Valor $^{2}$ \\
\hline$A_{1}$ Rotación de cultivos & 123 & 1,24 & 3 & 0 & 1 & 3 & 0,15 & 1,65 \\
$A_{2}$ Diversificación de cultivos & 126 & 1,26 & 4 & 0 & 1 & 4 & 0,15 & 1,26 \\
$B_{1}$ Cobertura vegetal & 121 & 1,34 & 4 & 0 & 0 & 4 & 0,05 & 1,34 \\
$B_{2}$ Tipo de suelo & 107 & 2,44 & 4 & 1 & 2 & 3 & 0,10 & 1,92 \\
$B_{3}$ Materia orgánica aplicada al suelo & 65 & 1,09 & 4 & 0 & 0 & 4 & 0,15 & 1,09 \\
$C_{1}$ Biodiversidad temporal & 124 & 0,57 & 2 & 0 & 1 & 2 & 0,10 & 1,15 \\
$C_{2}$ Biodiversidad espacial & 126 & 1,45 & 4 & 0 & 1 & 4 & 0,10 & 1,45 \\
$C_{3}$ Biodiversidad en variedades de papa & 126 & 1,06 & 3 & 0 & 0 & 3 & 0,10 & 1,41 \\
$C_{4}$ Incidencia de plagas y enfermedades & 126 & 3,44 & 4 & 1 & 4 & 3 & 0,10 & 2,63 \\
\hline
\end{tabular}

1 Datos de encuestas: 2014-2015.

2 Valores estandarizados para cada subindicador. 
algunas estrategias de control biológico de plagas en los campos de papa y el uso de inoculantes para recuperar especies perdidas a través del uso intensivo de plaguicidas. Mäder et al. (2002) sostienen que las parcelas agroecológicas pueden hacer que los ecosistemas agrícolas sean menos dependientes de insumos externos, incrementando su resiliencia. Los hallazgos de Oswald et al. (2010) sugieren que las cepas diazótrofas aisladas de la rizósfera de papa en los Andes del Perú tienen un enorme potencial como biofertilizantes, debido a sus características promotoras del crecimiento vegetal. Asimismo, la región central y sur del Perú ha sido reconocida como centro de diversidad genética de la papa (deHaan et al., 2010), por lo que se pueden utilizar los recursos de la agrobiodiversidad para mejorar su manejo en condiciones de campo.

\section{Impacto del uso de inoculantes como estrategia de manejo agronómico en la papa}

Para mejorar el índice de sostenibilidad ambiental, se evaluó una estrategia de manejo agroecológico en los sistemas de producción de papa en condiciones de Costa, que incluía el uso de inoculantes en los tubérculos semilla de papa. Se consideró que mediante esta estrategia sería factible incrementar los indicadores de sustentabilidad ambiental en las fincas productoras, logrando con ello reducir la dependencia de recursos de alto consumo energético y el riesgo asociado al cultivo de la papa en Costa, si se tiene en cuenta que en el país los sistemas de certificación de semilla de papa son todavía precarios.
- En el primer experimento, la inoculación de los tubérculos de papa cv. Única con la cepa Azotobacter sp. AZO 16M2 presentó diferencias significativas con respecto al control en cuanto a peso total de la biomasa, rendimiento de tubérculos por hectárea, peso comercial de tubérculos y menor daño por mosca minadora. Se concluyó que la aplicación de inoculantes con dicha cepa mejoró el comportamiento agronómico del cv. Única de papa bajo condiciones del valle de Cañete (Tabla 2).

- En el segundo experimento que se localizó en Quilmaná (Cañete), como resultado de la inoculación de tubérculos semilla con cepas bacterianas en los cultivares de papa Canchán, Perricholi y Única, se hallaron interacciones significativas con respecto al control para vigor vegetativo, porcentaje de inflorescencias por planta, peso del follaje por planta y peso de la biomasa total por hectárea, con un efecto estimulante en el desarrollo de estas variedades comerciales. Se destacó la Azotobacter sp. AZO16 M2 para promover el aumento del peso del follaje, biomasa total y floración en el cv. Perricholi, siendo el efecto específico de la inoculación con las cepas bacterianas, dependiente de los cultivares de papa (Figuras 2 y 3 ).

- $\quad$ El tercer experimento se desarrolló en el valle de Huaura-Sayán y se inocularon las mismas cepas bacterianas en los cultivares de papa Única y Canchán. Se observó que en el cv. Canchán el porcentaje de inflorescencias (\%) se incrementó por efecto de la inoculación con la

Tabla 2. Características productivas de la papa cv. 'Única' bajo efecto de rizobacterias en San Vicente, Cañete.

\begin{tabular}{lccccc}
\hline & Biomasa & Rendim $^{1}$ & P Comerc. & P Tubers & $\%$ Mosca \\
\hline Cepas & kg. ha ${ }^{-1}$ & kg. ha ${ }^{-1}$ & kg. pl ${ }^{-1}$ & kg. $\mathrm{p}^{-11}$ & $\sqrt{ }(\%+1)$ \\
\hline Azo16M2 & $18675 \mathrm{a}$ & $16550 \mathrm{a}$ & $0,51 \mathrm{a}$ & $0,59 \mathrm{a}$ & $3,16 \mathrm{a}$ \\
B13 & $14125 \mathrm{ab}$ & $12275 \mathrm{ab}$ & $0,31 \mathrm{bc}$ & $0,43 \mathrm{ab}$ & $4,47 \mathrm{ab}$ \\
Bac15MB & $17050 \mathrm{ab}$ & $14675 \mathrm{ab}$ & $0,47 \mathrm{a}$ & $0,54 \mathrm{ab}$ & $3,93 \mathrm{ab}$ \\
DZ22 & $14425 \mathrm{ab}$ & $12325 \mathrm{ab}$ & $0,39 \mathrm{ab}$ & $0,45 \mathrm{ab}$ & $4,81 \mathrm{~b}$ \\
Control & $13675 \mathrm{~b}$ & $10775 \mathrm{~b}$ & $0,22 \mathrm{c}$ & $0,38 \mathrm{~b}$ & $5,14 \mathrm{~b}$ \\
Standard Error & 1436,3 & 1331,4 & 0,04 & 0,05 & 0,41 \\
\hline
\end{tabular}

Medias con la misma letra en columnas no difieren estadísticamente $(P>0,05)$. PComerc. $=$ peso comercial de tubérculos por planta $(\mathrm{kg})$, PTubers = peso fresco de tubérculos por planta $(\mathrm{kg})$, Rendim $^{1}=$ rendimiento $(\mathrm{kg})$ proyectado para una densidad de 30000 plantas ha $^{-1}$, Biomasa $=$ peso total de la biomasa (tubérculos + follaje) proyectado por hectárea $(\mathrm{kg}), \%$ Mosca $=$ porcentaje of plantas dañadas por mosca minadora a los 60 días, Datos transformados a $\sqrt{ }(\%+1)$. 

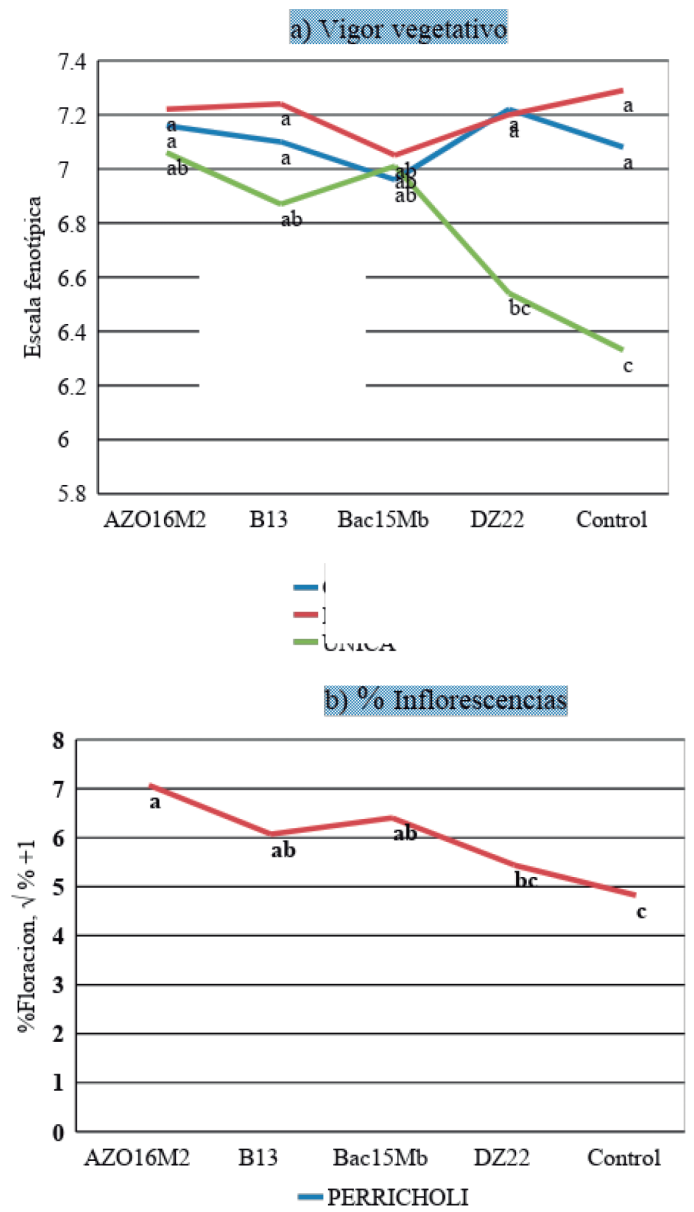

Figura 2. Interacción entre las variedades de papa y el efecto de inoculación con cepas bacterianas para (a) vigor vegetativo, (b) porcentaje de inflorescencias en la localidad de Quilmaná (Cañete). Medias con letras iguales no son estadísticamente diferentes $(P>0,05)$.

cepa Bac15Mb (Bacillus amyloliquefaciens) en relación con el control (Figura 4). Asimismo, se halló que al inocular los tubérculos semilla de papa en los cv. Única y Canchán, la incidencia de mosca minadora (Lyriomiza huidobrensis) se redujo relativamente por efecto de las cepas bacterianas en relación con el control, tal como se puede apreciar en la Figura 5.

\section{Discusión}

Desde el punto de vista de la sustentabilidad y en función del análisis multicriterio utilizado en la investigación, los valores de los indicadores nos muestran que el sistema de producción en
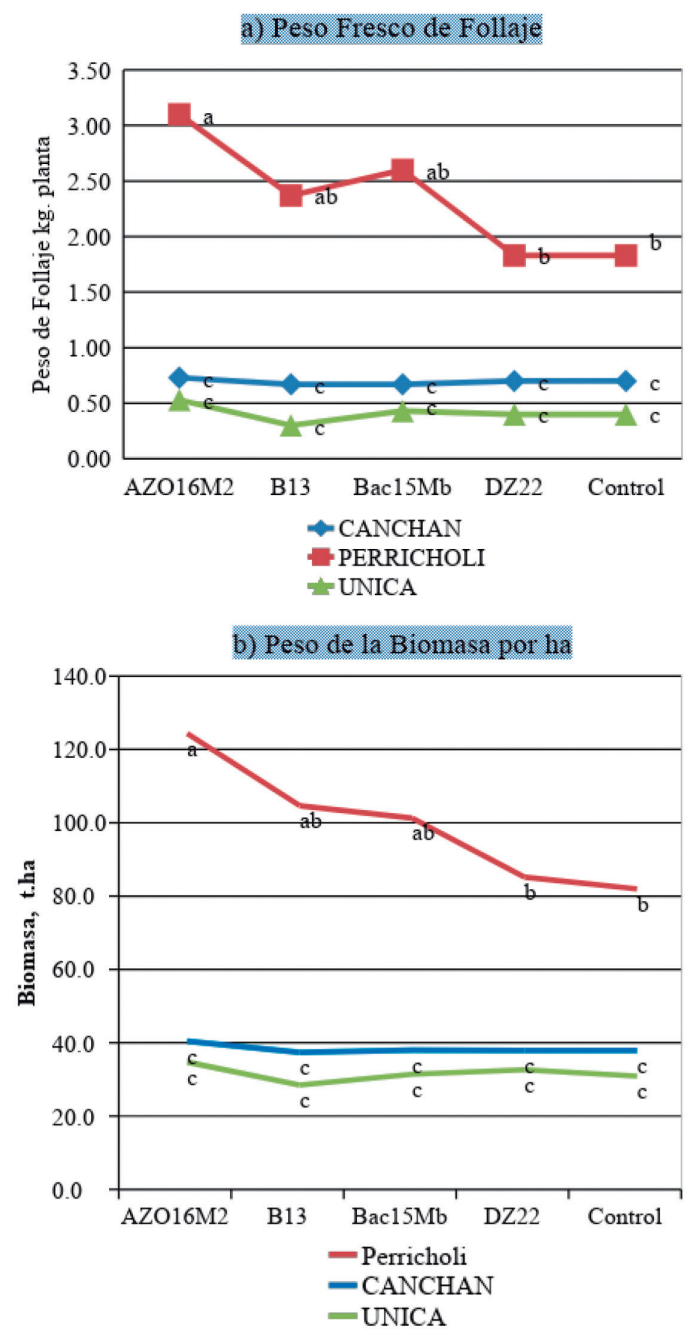

Figura 3. Interacción entre cultivares de papa y el efecto de inoculación con cepas bacterianas para (a) peso fresco del follaje y (b) peso de la biomasa en la localidad de Quilmaná (Cañete). Medias con letras iguales no son estadísticamente diferentes $(P>0,05)$.

las fincas productoras de papa en la región Lima necesita un ajuste para alcanzar niveles apropiados de sustentabilidad. Con respecto a la importancia del cultivo de papa, hay que indicar que el país como centro principal de diversidad de la papa y sus parientes silvestres ocupa un lugar expectante en cuanto a área cultivada, con un total de 318 . 000 hectáreas, la mayor parte en la zona andina. Aunque en la costa central del Perú donde se ubica la región Lima se cultivan no más de 8. 000 hectáreas (MINAGI, 2015), esta superficie se maneja con tecnología media a alta, con rendimientos que duplican la media nacional con un alto uso energético. 


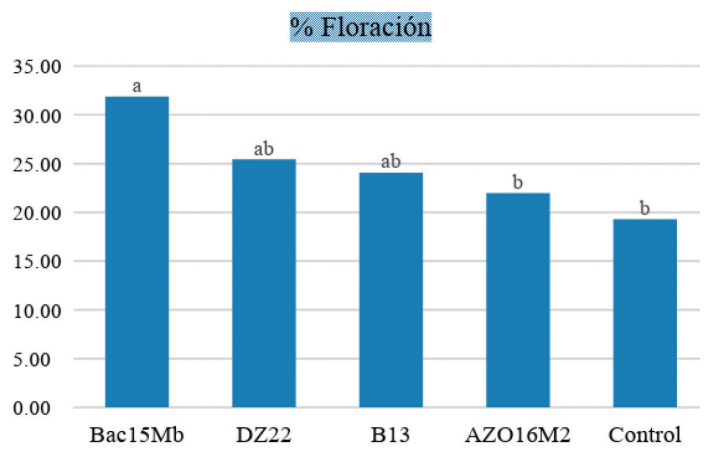

Figura 4. Efecto de inoculación de tubérculos semilla con cepas bacterianas sobre el porcentaje de floración en cv. Canchán (Huaura-Sayán). Medias con letras iguales no son estadísticamente diferentes $(P>0,05)$.

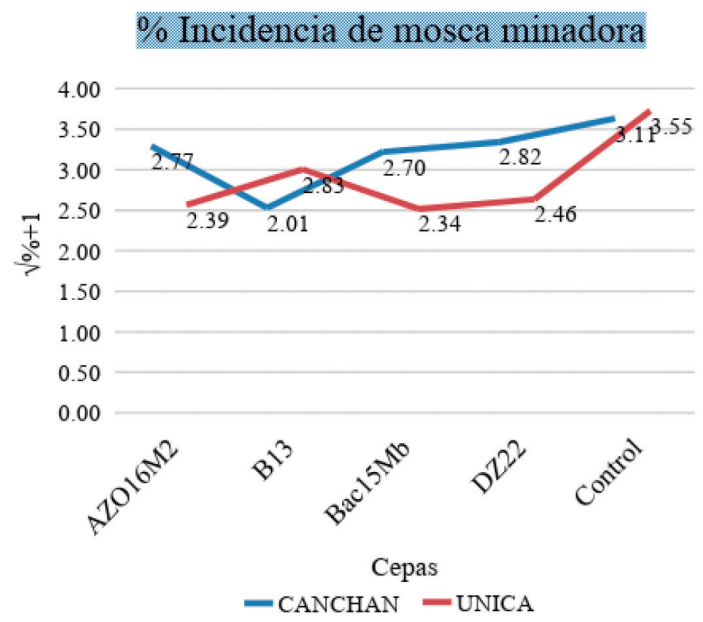

Figura 5. Incidencia de mosca minadora (Lyriomiza huidobrensis) bajo efecto de inoculación de cepas bacterianas en dos cultivares de papa (Huacho). Datos transformados a $\sqrt{ } \%+1$.

Entre los criterios desarrollados y que se resumen en la Tabla 3, los aspectos del manejo agroecológico en la papa mediante el uso de microorganismos se han tomado en cuenta por los siguientes motivos:

- Existe evidencia científica suficiente de que mediante la simbiosis regulada por el medio ambiente entre las plantas y los microorganismos, es posible reducir el uso de insumos de alto consumo energético que normalmente tienen impacto ambiental, como fertilizantes y agroquímicos, mitigando sus efectos nocivos en el ecosistema. Este proceso incluye la fijación biológica del nitrógeno atmosférico, solubilización y/o absorción de fósforo, resistencia sistémica inducida y la inmunidad vegetal, entre otros aspectos fisiológicos favorables al desarrollo de las plantas (Naqqash et al., 2016; Castillo et al, 2016; Hanif et al, 2015).

- La identificación, caracterización y producción de los microorganismos involucrados en el proceso simbiótico con las plantas ha avanzado notablemente en los últimos 10 años (Oswald et al. 2010; Calvo et al, 2010; Ortuño et al., 2018).

- Existe una tendencia hacia la reducción de la biodiversidad en todas sus variantes, lo que está ocasionando erosión genética, como consecuencia de la necesidad de uniformidad en las cosechas, sobre todo en la papa, en la que el mercado es exigente en este aspecto. $\mathrm{La}$ diversidad microbiana existente y asociada al cultivo de papa es muy amplia y puede ayudar a reducir los efectos derivados del monocultivo, fortaleciendo el sistema de producción (Sessitsch $\&$ Mitter, 2015).

- La población microbiana del suelo puede ayudar a reducir la erosión de suelos degradados por la excesiva labranza o durante el manejo convencional del cultivo, favoreciendo el restablecimiento de la fertilidad, la capacidad de retención de nutrientes y la disponibilidad de elementos necesarios para el cultivo de la papa (Turnbull et al., 2014; Kennedy \& Smith, 1995).

Sin embargo, y de acuerdo a la evidencia presentada en la investigación, aún existen restricciones para el uso de la inoculación con microorganismos en el cultivo de papa. Podemos señalar que los resultados hallados mediante el uso de inoculantes en la papa y otros cultivos, se ven obstaculizados a menudo por falta de eficacia y fiabilidad (Van Loon, 2007) y ello dificulta la difusión de esa innovación. Este hecho contrasta con lo ocurrido en otras especies como las leguminosas de grano, en las que el uso de inoculantes se ha extendido.

\section{Conclusiones}

Se determinó que las fincas productoras de papa en la región Lima tienen un bajo nivel de sustentabilidad ambiental, con un valor de 1,52 
Tabla 3. Grupos taxonómicos microbianos asociados a diversos atributos en cultivares de papa ${ }^{1}$.

\begin{tabular}{|c|c|c|c|c|c|}
\hline Cultivares de papa & $\begin{array}{l}\text { Grupo taxonómico } \\
\text { microbiano }\end{array}$ & Ambientes & Países & Atributos/Efectos ${ }^{2}$ & Referencias \\
\hline $\begin{array}{l}\text { Yungay, Canchan } \\
\text { Desiree, Única }\end{array}$ & Bacillus sp. & $\begin{array}{l}\text { Invernadero, } \\
\text { Сатро }\end{array}$ & Perú & $\begin{array}{l}\text { Tuberización } \\
\text { temprana, } \\
\text { rendimiento }\end{array}$ & Oswald et al. (2010) \\
\hline Peruanita & Bacillus subtilis & In vitro & Perú & Biofertilizante & Calvo et al. (2010) \\
\hline Ccompis, Andina & Bacillus, Azotobacter & Campo & Perú & Rhizoctonia & Arcos y Zúñiga (2015) \\
\hline $\begin{array}{l}\text { Fripapa, Yungay, } \\
\text { Waycha }\end{array}$ & $\begin{array}{l}\text { Pseudomonas, } \\
\text { Paenibacillus, Bacillus }\end{array}$ & Campo & $\begin{array}{l}\text { Región } \\
\text { Andina }\end{array}$ & $\begin{array}{l}\text { Rendimiento+, } \\
\text { VOCs }\end{array}$ & Vellivelli et al. (2014) \\
\hline Kuroda & Azospirillumsp. TN10 & $\begin{array}{l}\text { In vitro, } \\
\text { Hidroponía }\end{array}$ & Pakistán & $F B N, A I A$ & Naqqash et al. (2016) \\
\hline Shepody & N.D. & $\begin{array}{l}\text { In vitro, } \\
\text { campo }\end{array}$ & Canadá & $F B N, A I A$ & Turnbull et al. (2014) \\
\hline Innovator & Bacillus subtilis KPS-11 & In vitro & Pakistán & Solubilización-P & Hanif et al. (2015) \\
\hline Waycha & $\begin{array}{l}\text { Bacillus subtilis, G. } \\
\text { fasciculatum }\end{array}$ & Cатро & Bolivia & $\begin{array}{l}\text { Rhizoctonia, } \\
\text { Rendimiento+ }\end{array}$ & Main \& Franco (2016) \\
\hline Desirée & Azospirillum & Cатро & Chile & FBN, Rendimiento+ & Castilllo et al. (2016) \\
\hline Golden Wonder & Glomus intraradices & $\begin{array}{l}\text { In vitro, } \\
\text { Invernadero }\end{array}$ & Irlanda & $\begin{array}{l}\text { Rendimiento+, } \\
\text { tuberización }\end{array}$ & Duffy \& Cassells (2000) \\
\hline Superior & Glomus intraradices & Campo & $\begin{array}{l}\text { Reino } \\
\text { Unido }\end{array}$ & $\begin{array}{l}\text { Rendimiento+, } \\
\text { tuberización }\end{array}$ & Douds et al. (2007) \\
\hline
\end{tabular}

\footnotetext{
${ }^{1}$ Elaboración propia basada en la bibliografía disponible. N.D., no determinado; Vigor, vigor vegetativo; Tuberización, inducción de tuberización; Rhizoctonia, resistencia a R. solani; Biomasa, producción de biomasa; Rendimiento+, alto rendimiento de tubérculos; FBN, Fijación biológica de nitrógeno; AIA, producción de ácido indol acético, VOCs, producción de compuestos orgánicos volátiles; MS, materia seca de los tubérculos, PFollaje, peso fresco del follaje.
}

en la escala ponderada de indicadores utilizada, y que es necesario implementar medidas que reduzcan la vulnerabilidad del cultivo en cuanto a la conservación de la vida del suelo y manejo de la agrobiodiversidad. Se considera que el uso de inoculantes se presenta como una alternativa de manejo agronómico sustentable en el cultivo de papa, ya que mediante la inoculación de los tubérculos semilla de papa con la cepa Azotobacter sp. y otras rizobacterias se obtuvieron diferencias significativas con respecto al control sin inoculación, aumentando el rendimiento de tubérculos y el peso comercial por hectárea, con un menor daño por mosca minadora (Liriomyza huidobrensis) en condiciones de la costa central. Se concluye que la utilización de bacterias promotoras del crecimiento en la papa puede ayudar a reducir la vulnerabilidad del cultivo, incrementando el nivel de sustentabilidad ambiental a nivel de finca.

\section{Agradecimientos}

Se agradece al Vicerrectorado de Investigación de la Universidad Nacional José Faustino Sánchez Carrión por el financiamiento del proyecto a través del Fondo de Desarrollo Socioeconómico de Camisea - FOCAM, al LEMYB Marino Tabusso (UNALM) por proporcionar las cepas bacterianas utilizadas en la investigación, al Laboratorio de Suelos y Fertilizantes (UNALM) por proveer los análisis de caracterización de suelos y a los graduados de Agronomía Luis Luyo Sánchez, Juan Carlos Custodio y Mónica González por su participación en los ensayos agronómicos. 


\section{Literatura Citada}

Altieri, M.A

1997. Enfoque Agroecológico para el Desarrollo de Sistemas de Producción Sostenibles en los Andes. Ed. CIED. LimaPerú. 92 p.

Arcos, J.; Zúñiga, D.

2015. Efecto de rizobacterias en el control de Rhizoctonia solani en el cultivo de papa. Ecología Aplicada, 14(2):95-101.

Brussaard, L., De Ruiter, P.C.;Brown, G.G.

2007. Soil biodiversity for agricultural sustainability. Agriculture, ecosystems \& environment, 121(3): 233-244.

Calvo, P.; Ormeño-Orrillo, E., Martínez-Romero, E.; Zúñiga, D. 2010. Characterization of Bacillus isolates of potato rhizosphere from andean soils of Peru and their potential PGPR characteristics. Brazilian Journal of Microbiology 41: 899-906

Castillo, C.; Huenchuleo, M.J.; Michaud, A.; Solano, J.

2016. Micorrización en un cultivo de papa adicionado del biofertilizante Twin-N establecido en un Andisol de la Región de La Araucanía. Idesia (Arica), 34(1): 39-45.

de Haan, S.; Núñez, J.; Bonierbale, M.; Ghislain, M. 2010. Multilevel agrobiodiversity and conservation of Andean potatoes in central Peru species, morphological, genetic, and spatial diversity. Mountain Res. Dev., 30: 222-231.

Douds Jr., D.D.; Nagahashi, G.; Reider, C.; Hepperly, P.R.

2007. Inoculation with arbuscular mycorrhizal fungi increases the yield of potatoes in a high P soil. Biological agriculture \& horticulture, 25(1): 67-78.

Duffy, E.M.; Cassells, A.C.

2000. The effect of inoculation of potato (Solanum tuberosum L.) microplants with arbuscular mycorrhizal fungi on tuber yield and tuber size distribution. Applied Soil Ecology, 15(2): 137-144. FAO.

2008. Gestión de las plagas y enfermedades. Secretaría del Año Internacional de la Papa. International Year of the Potato celebrated in 2008. FAO. Roma.

Hanif, M.K.; Hameed, S.; Imran, A.; Naqqash, T.; Shahid, M.; Van Elsas, J.D.

2015. Isolation and characterization of a $\beta$-propeller gene containing phosphobacterium Bacillus subtilis strain KPS-11 for growth promotion of potato (Solanum tuberosum L.). Front. Microbiol. 6(583). doi: 10.3389/fmicb.2015.00583

Kennedy, A.C.; Smith, K.L.

1995. Soil microbial diversity and the sustainability of agricultural soils. En: The significance and regulation of soil biodiversity. Springer Netherlands. pp. 75-86.

Kroschel, J., Mujica, N., Alcázar, J., Canedo, V., \& Zegarra, O. 2012. Developing integrated pest management for potato: experiences and lessons from two distinct potato production systems of Peru. In Sustainable potato production: global case studies Springer Netherlands. pp. 419-450.
Mäder, P.; Fliessbach, A.; Dubois, D.; Gunst, L.; Fried, P.; Niggli, U.

2002. Soil fertility and biodiversity in organic farming. Science, 296(5573): 1694-1697.

MINAGRI.

2015. Intenciones de siembra: Campaña Agrícola 2015-2016.

DGESEP. Ministerio de Agricultura y Riego. Lima, Perú. $20 \mathrm{p}$.

Naqqash, T.; Hameed, S.; Imran, A.; Hanif, MK.; Majeed, A.; van Elsas, J.D.

2016. Differential Response of Potato toward Inoculation with Taxonomically Diverse Plant Growth Promoting Rhizobacteria. Front. Plant Sci. 7:144. doi: 10.3389/ fpls.2016.00144

Ortuño, N.; Córdoba, M.; Claros, M.; Castillo, J.A.

2018. Evaluación de bacterias endófitas de papa nativa (Solanum tuberosum L.) y el desarrollo de un biofertilizante. Revista Latinoamericana de la papa, 22(1): 12-37.

Oswald, A.; Calvo, P.; Zúñiga, D.; Arcos J.

2010. Evaluating soil rhizobacteria for their ability to enhance plant growth and tuber yield in potato. Ann Appl Biol., 157 (2010): 259-271.

Prashar, P.; Kapoor, N.; Sachdeva, S.

2014. Rhizosphere: its structure, bacterial diversity and significance. Reviews in Environmental Science and Bio/ Technology, 13(1): 63-77.

Sarandón, S.J.

2002. El desarrollo y uso de indicadores para evaluar la sustentabilidad de los agroecosistemas. En: Santiago J. Sarandón (editor): Agroecología. El camino hacia una agricultura sustentable. Ediciones Científicas Americanas 20: 393-414.

Sarandón, S.J.; Flores, C.C.

2014. Agroecología: bases teóricas para el diseño y manejo de agro ecosistemas sustentables. 1a ed. Universidad Nacional de La Plata. La Plata, Argentina. 467 p.

Sessitsch, A.; Mitter, B.

2015. 21st century agriculture: integration of plant microbiomes for improved crop production and food security. Microbial biotechnology, 8(1): 32-33.

Turnbull, A.L.; Campbell, I.; Lazarovits, G.

2014. Resistance of bacterial communities in the potato rhizosphere to disturbance and its application to agroecology. Soil Biology and Biochemistry, 79: 125-131.

Velivelli, S.L.; Sessitsch, A.; Prestwich, B.D.

2014. The role of microbial inoculants in integrated crop management systems. Potato Research, 57(3-4): 291-309.

Van Loon, L.C.

2007. Plant responses to plant growth-promoting rhizobacteria. Eur. J. Plant Pathol., 119: 243-254. 
